\title{
How Useful Are Multimodal Texts in Motivating Vietnamese Primary School Children in Learning English Vocabulary?
}

\author{
Loc Tan Le \\ Vietnam USA Society, Ho Chi Minh City, Vietnam
}

\begin{abstract}
Motivating young learners in learning vocabulary is not easy, especially in the context that children learning English at weekends in language schools in Vietnam feel stressful and tired after schooldays at their primary schools. But if we fail to do that, we are unable to help them improve their language skills. As a result, this action research examined the roles of multimodal texts in motivating Vietnamese primary school children in learning English vocabulary. It was conducted in two classes at a language school where the researcher has been teaching English for five years and a conclusion was withdrawn that in spite of challenges facing the teachers multimodality engaged the primary school children, both boys and girls, at different ages in learning vocabulary.
\end{abstract}

Keywords: multimodal texts, multimodality, motivation, vocabulary, primary school children

\section{Introduction}

In Vietnam, the traditional teaching approach focusing on grammar, accuracy, reading, and tests has "rooted" in schools for years. Although the new approach—Communicative Language Teaching—focusing on communication and fluency has been introduced in the recent years, the former has still played a dominated play, particularly in public schools. Another approach, as described in Lewis and McCook's (2002) research, also formed in Vietnam in the past few years is the combination of the two approaches above. It covers fluency, accuracy, oral language, written language, and tests. The author's language school has utilized this approach with the aims of helping learners including children who are facing different English tests in their school communicate well in English and improve their scores in exams.

In that context, the author and his colleagues have been facing increasing challenges which sometimes bring about some tension. First, all teachers are assessed by two following main factors. The first one is to meet the requirements of teaching quality which are evaluated via Training Quality Manager's observations. The second one challenging us more is how highly we are evaluated by learners via the surveys conducted in the end of each course. Sometimes, we try our best to meet the former but fail to achieve the later. Another challenge is that most classes for children are held at weekends. At this time, most of them are overloaded with their studying for five or six days a week at their primary school. Hence, motivating them to learn appropriately is always a big problem we have to deal with.

From some aforementioned challenges, the author's primary concern is how to motivate primary school children in learning vocabulary. Before teaching them grammar, reading, listening, or speaking, we are requested to clarify the meanings and pronunciation of words. However, they usually ignore what we try to do

Loc Tan Le, master, Vietnam USA Society. 
for them. When we ask them to listen and repeat words, some of them whisper, some do not open their mouth, some enthusiastically speak out the words but just for one time. As a result, the author realizes that innovation needs to be done in his classrooms with the hope that his students get excited in learning vocabulary, because LU (2008) confirmed that "If language structures make up the skeleton of language, then it is vocabulary that provides the vital organs and the flesh”.

Also, from what Chappelle (2003, p. 67), Marsh and Singleton (2009), and Robins (2011) commented that learning under the context of technology development not only relies on written texts, but is also supported by a variety of texts including sounds, gestures, pictures, and games, etc., known as multimodal texts, the author would like to investigate how the modes of texts including written texts, visual texts (flashcards and images searched from the internet), and activities-like games designed with the software of PowerPoint can motivate Vietnamese primary school children at different ages in learning new words by the way of addressing these following questions: (1) How can those texts change the children's attitudes towards learning vocabulary?; (2) Do the girls and the boys have the same level of motivation?; (3) Which text motivates children most?; (4) How should multimodal texts be used in vocabulary teaching and learning?; and (5) How do the children acquire vocabulary under the application of multimodality?.

With attempt to provide a background for what the author did, he first reviews some relevant literature on vocabulary teaching and learning, motivation, multimodality, and its roles in teaching and learning vocabulary investigated by previous research articles. The author then outlines the methods used in his research. The author will also describe his participants, instruments, and procedures in this section. The next section will show his findings; the section after that will include some discussion; through the two of which, the questions listed above will be addressed. Finally, some conclusion will be drawn and some recommendations will be also made.

\section{Literature Review}

\section{Motivation}

Motivation can be said to play a decisive role in literacy learning in general and second language in particular. Motivation, as defined by Vincent (1984) quoted in Al-Haj (2011), is what catches someone's interests, draws their attention, and makes them act. Ornstein (1995) described in detail that students who are not motivated act in different ways such as being distracted, quickly withdrawing from activities, daydreaming, doodling, looking out the window, getting disruptive, etc.. He also informed that those students rarely volunteer to answer questions but usually keep quiet unless called by their teacher. Consequently, Gomleksiz (2001) stated that teachers find it difficult to teach those students second language. That results in an argument by LI (2009) and Al-Haj (2011) that motivation in learning has a significant influence on second language acquisition, because learners who are interested in learning language devote their time to it and have suitable strategies to achieve their learning goals.

In terms of motivation classifications, Landen and Willems (2001) claimed that intrinsic motivation is better for learning than extrinsic one because the later mainly depends on extrinsic rewards; therefore, it is not available if there is an absence of the rewards. Exploring the factors affecting motivation, Yeung, Lau, and Nie (2011) made a remarkable comment that gender, age, and motivation have a close relationship: Boys are more motivated than girls, and the older are less motivated than the younger. 


\section{Vocabulary Teaching and Learning}

As discussed above, motivation is really necessary for second language acquisition. This results in a judgment that it can play an important role in teaching and learning vocabulary. Allen (1983) informed that teachers find it hard to teach their students vocabulary because of the fact that the students feel they do not need to learn it. Therefore, the teachers' duty is to create a sense of need for learning vocabulary by different techniques for "showing the meanings of words" and "drawing attention to meanings before drilling words" (pp. 8-15). Allen (1983, pp. 33-52) also suggested some useful techniques that help students learn words effectively, including real objects, pictures, actions, and especially games which make students enthusiastic about learning and make them feel that they need to learn words to play the games. More interestingly, Sharma and Barrett (2007, pp. 22-38) provided technology-related techniques in teaching and learning vocabulary. Those are images searched from the web pages and electronic games that can be alternative to books and print-based activities.

Discussing how to teach and learn vocabulary, McCarten (2007, p. 21) claimed that repeating a word aloud is one of the effective ways to help students remember it. Teachers are also suggested to create more opportunities for their students to recall a word, not just to see it over and over. Moreover, LU (2008) recommended that teachers get students to interact with words more than just repeat them. She especially referred to creating "a mental image of a word's meaning” so that students can use their mental processing in a deeper and richer way, leading to a result that they can remember the word.

Furthermore, Jalongo and Sobolak (2011) noticed that children who learn English as their second language are at risk of failing to reach vocabulary proficiency, because they hardly find any chances of gaining new words at home. Accordingly, they propose the solutions that the teachers, firstly, find ways to engage the students to learn vocabulary in classroom. Secondly, the procedures such as repetition and reading words aloud as argued in the papers reviewed above should be combined with enactive, iconic, and symbolic modes in teaching vocabulary.

\section{Multimodal Texts and Their Roles in Vocabulary Teaching and Learning}

The techniques suggested by Allen (1983), and Sharma and Barrett (2007), as mentioned in the previous subsection, are the forms of multimodality used in teaching and learning vocabulary. Besides, Marsh and Singleton (2009), and Wyatt-smith and Kimber (2009) informed that multimodal texts and new technologies harmonize with each other under the context of technology development. According to Bearne and Wolstencroft (2007), Robins (2011), and Lancaster and Rowe (2011), multimodality is so rich in modes including gesture, visual images, sound, games, written language, objects, and other semiotics.

However, a number of following papers present that the application of multimodal texts pose considerable challenges for both teachers and students. As Shenton and Pagett (2007) put it, teachers have to spend much of their time on preparing materials. In addition to the requirement of excellent software, HAI and LI (2007) stated that teachers need some knowledge of technology. Moreover, Honan (2008) reported that the adoption of digital texts in classroom can cause a problem that the teachers cannot cover syllabus documents, because they do not have enough time in classroom. Sharing the same point of view of HAI and LI (2007), Graham (2009) argued that computer games enhance students' literacy, but the challenge both teachers and students face is that they need to learn "new skills". Agreeing with Honan (2008) and Graham (2009), Harrett and Benjamin (2009) pointed out in their paper that games, videos, and DVD materials motivate students in learning on the one hand; on the other hand, teachers are reluctant to adopt them because 
of their lack of knowledge of technology. Impressively, Ryan, Scott, and Walsh (2010) revealed that some teachers worry that their role will be pushed to the margins of classroom.

Despite some challenges posed by the adoption of multimodality, it still plays a significant role in education. As a result, it has been investigated by a variety of studies; however, their findings are not convergent. Acha (2009) examined the roles of verbal annotations, visual annotations and both of them in teaching children new words and concludes that using verbal annotations is "more effective" than using visual annotations or both. The reason, as she explained, is that it takes children less time to recognize what a word means. Using the same instruments as Acha's (2009), but Shahrokni (2009) recorded a conflicting finding that the combination of texts and images results in improving students' vocabulary acquisition. In spite of using different instruments, videos with subtitles, Harji, Woods, and Alavi (2010) supported Shahrokni (2009) that those instruments enhance students' level of second language vocabulary. In the same way, Sabet and Shalmani (2010) assessed the adoption of videos, spoken texts, and visual texts for teaching vocabulary and then comment in their research that videos combined with visual texts result in better learning: Students improve their "memorization and retrieval of vocabulary". Rezaee and Shoar (2011) compared video clips combined with text, picture with text, and text without annotation with each other in their research on the roles of multimedia in teaching vocabulary. Their study indicates that the combination of text and video clips is the most effective and the text without annotation is the least effective. In general, the studies above, except for the one by Acha (2009), proclaimed that multimodality works well with vocabulary teaching and learning.

Another study by Zarei and Khazaie (2011) reported some findings which differ from what is reviewed above can be called "neutral". They evaluate how students with different abilities (high-visual, high-verbal, low-visual, and low-verbal) acquire second language vocabulary with different modes of texts (no annotation, pictorial, and written annotations). A conclusion drawn is that students with high-visual ability learn vocabulary better with pictorial annotation, whereas students with high-verbal ability learn words better with written annotation. Meanwhile, no annotation is suitable for the ones with both low-visual and low-verbal abilities.

The research papers reviewed did not offer the answers in the same direction; hence, the question about whether multimodal texts are useful for teaching and learning vocabulary has not been answered satisfactorily. More importantly, how multimodality can motivate learners in learning vocabulary has not been examined carefully either.

\section{Methodology}

\section{Methods}

This action research adopted three different methods to form a triangulation, as R. E. D. Cotton, Stokes, and A. P. Cotton (2010) suggested in their article, with the aim to get as much reliable data as possible. Observing, according to Tomal (2010, p. 37), including direct observations and journals was used to record children's performance in the context of using multimodality. Wilmot (1979) announced that observing participants gives researchers an overall and realistic look. In addition, the teacher's assistant journals were also examined to get information which may be missed in the teacher journals.

Semi-structured interviewing is another necessary method combined with observing to form that triangulation. Kortesluoma, Hentinen, and Nikkonen (2003) found that children interviews help researchers explore what children think in their mind. Furthermore, they also informed that relying on adults is also a good 
way to know about children's thoughts, feelings, and experiences. That is right to Vietnamese children, because the author's students usually shared their feelings with his assistants. Hence, face-to-face interviews with the author's assistants were also held with the purpose of getting their opinion on how multimodality works in classroom and children's thoughts.

Finally, assessing is also in need to reflect how the children acquired the words they had learned with multimodal texts. At the planning stage, doing students' test paper assessment was not put in the author's consideration because of the fact that standard tests in Vietnamese context usually put children under pressure. However, the time budget for conducting the research was close to the time for a midterm test designed and required by the school. As a result, their test papers were also examined with the aim to evaluate their ability of recalling the words they had learned. Moreover, how they did exercises designed in their students' book after learning new words was recorded in the teacher journals to evaluate the children's vocabulary acquisition. Then their cards for writing words were also collected for the same purpose.

Although a triangle was expected to be constructed, there were some limits that were thought to partly influence the findings. The first one was the time for holding children interviews was unreasonable. The reason for this was that the interviews were conducted in the break time, so the children focused less on answering questions but more on the games their friends were playing outside and the food and drinks they looked forward to buying. It is noticed that appointments could not be made with them after or before the school time. The second one was that some important events might be missed in the teacher and teacher's assistant journals, because the teacher wrote them in the break time of each section and the teacher's assistants observed how children were involved in three main activities conducted to teach vocabulary but not the activities of speaking, listening, or reading after that due to the fact that they were busy with their paper work.

\section{Participants and Research Context}

The participants in this research were 34 primary school children at the age of seven to 11 studying English at Vietnam USA Society, a language school, and two teacher's assistants. All children took the classes held on Sunday mornings. One class (class A) with 17 children (six boys and 11 girls) at the age of seven to eight learning with the textbook Everybody up 1 (Jackson \& Sileci, 2012a) was from 7:45 a.m. to 9:45 a.m.. Another one (class B) with another 17 children (five girls and 12 boys) at the age of nine to 11 learning with the text book Everybody up 3 (Jackson \& Sileci, 2012b) was from 10:00 a.m. to 12:00 a.m.. At the time this study was conducted, the students in both classes had finished one of four units. From the whole number of participants, one boy and one girl in each class were selected randomly for interviews. Two lists of students' name were shown to one of the author's colleagues who did not know his students, and the colleague was asked to choose one boy and one girl from each list (the boy and the girl in class A were known as boy A and girl A; similarly, the boy and the girl in class B were known as boy B and girl B).

\section{Instruments}

As described, multimodal texts include different modes of texts, but this study focused on some of them which were considered suitable for the lessons from the text books. They were written texts, flashcards, and images including still and moving images searched from the internet to clarify the meanings and pronunciation of the words in the lessons. They were also used as sources to design learning activities-like games to encourage children to follow the procedures of teaching and learning vocabulary. In addition, the software of PowerPoint was used for designing games ("Pelmanism" and "The wheel of fortune") and presenting images. 
Importantly, projectors and computers in each classroom which are usually served for teenager and adult classes were agreed to be for serving this research.

\section{Procedures}

Data were collected within three sections (around 110 minutes for each section in which the time for teaching and learning vocabulary is around 50 minutes). In the first and second section, the vocabulary in the same topic was taught by using flashcards and images to clarify the meanings of words and their pronunciation. After that, three activities-like games were introduced with the aims of encouraging the children to repeat, write, and remember the words.

The first one was designed by sticking the flashcards on the board in rows. Then a story was made up to draw the children's attention to this activity. For example, with the words for animals (class A), a story was that "Imagine that one day your parents take you to go to the zoo. When you get there, you see a zookeeper serving a meal for animals. He is working very hard and he is very tired. Please help him”. Then the class was divided into two teams: team A with a small red ball and team B with a small blue ball (the balls were imagined as the food). One student from team A and another one from team B held their ball in their hands. They listened to a word said by their teacher and then threw their ball into the correct flashcard on the board. The student threw the ball into the correct flashcards more quickly got one point for his/her team (that means he/she brought the food to the animal more quickly). And then he/she is the person who said the word for two other students on the next turn. This activity lasted about 15 minutes in each class.

The second one which is known as "Pelmanism" (see Figure 1) was designed with the software of PowerPoint. One team selects any two windows by saying the numbers presented on them and the teacher then clicks the mouse to open these two windows. If they are matching (see an example in Figure 1), a point is given to that team and they continue until two windows they select are not matching. That means they lose their turn and another team do the same procedure. Each class did this activity within around 10 minutes.

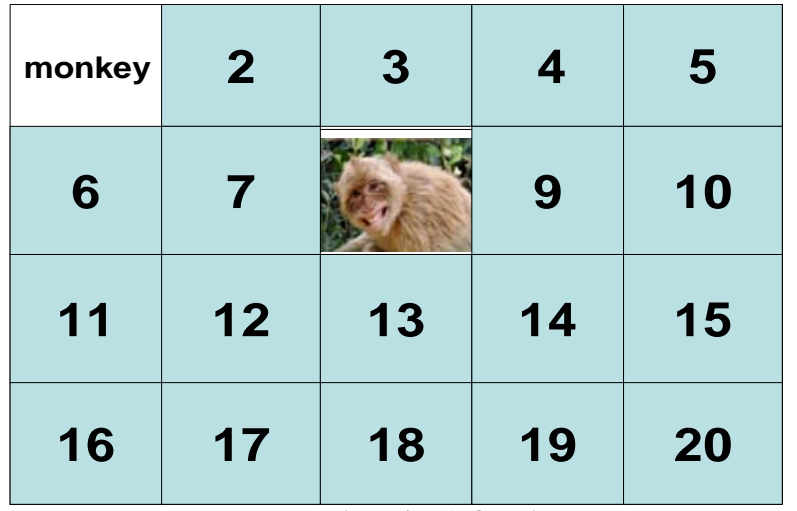

Figure 1. "Pelmanism” for class A.

The third one which was also designed with PowerPoint is called "The wheel of fortune" (see Figure 2). The teacher shows the whole class the definition of a word (see an example in Figure 2). Then one of the students in one team guesses one letter that he/she thinks it may constitute the word. If he/she guesses it correctly, the teacher clicks the mouse to open the window(s) to show the letter(s) to the class. After that, that student clicks the mouse on "spin" button to spin the wheel and he/she then clicks the mouse again to stop the wheel. How many points his/her team get depends on where the hand is. About 10 minutes were spent for this activity in each class. 
The same procedure with different topic (the chores) was also used for another class (class B). How the students participated in the activities in the section of vocabulary teaching, and how they used the words they had learned with multimodality to do listening, speaking, or reading activities designed in the text books were observed and recorded in the teacher journals. In the teacher's assistant journals, only the former was covered, because teacher's assistants did not have enough time to do some paper work required by the school.

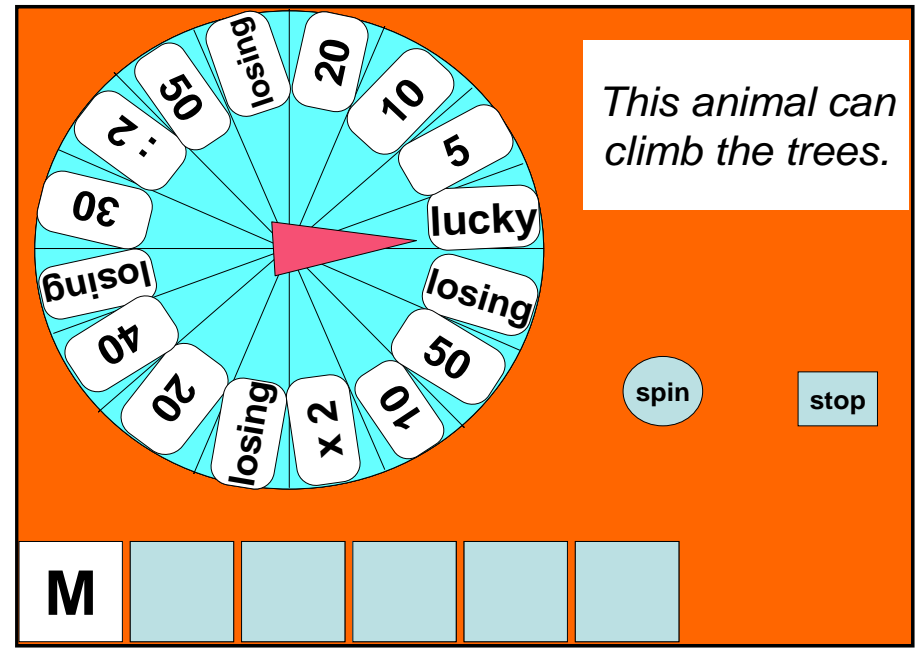

Figure 2. "The wheel of fortune" for class A.

In the third section, the moving images which were used to clarify the meanings and pronunciation of the words taught in the first and second section were put in the PowerPoint slide(s) to help the children review them firstly (see an example in Figure 3). After that, they saw those moving images presented on PowerPoint slide(s) again and wrote the words (or phrases) describing the images down on their card. Three students finishing their work first without spelling mistakes won the prize. Finally, all of their cards were collected for assessment (see an example in Figure 4).

In the middle of the third section (in break time), student interviews were conducted. In the end of the third section, teacher's assistants were interviewed. A week after that, the students in both classes had a midterm examination. How they recalled the words they had learned with multimodal texts reflected in their test paper was examined.

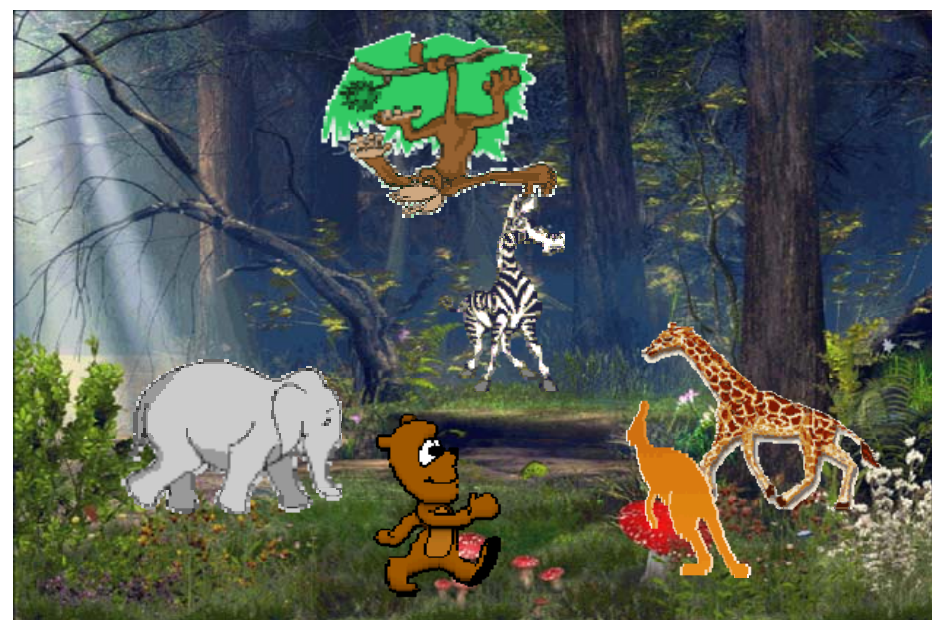

Figure 3. A slide with moving images presented in class A. 

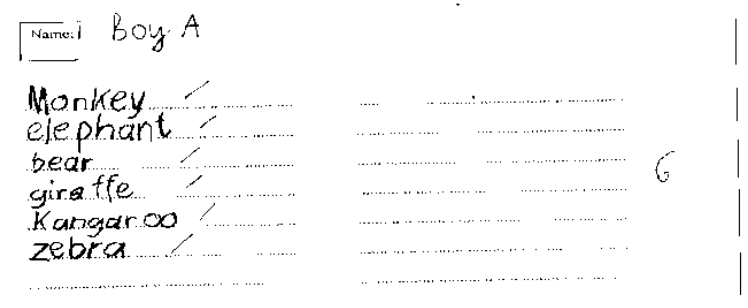

Figure 4. Boy A’s writing cards (class A).

\section{Findings}

Compared to what happened previously, the classroom atmosphere changed fundamentally. Most students in two classes were motivated a lot. They were curious when the author pulled the screen down and opened a projector. Some boys asked the author: "What are you doing, teacher? Watching movies?” (personal communication, October 9, 2011). The author said: "Playing games” (personal communication, October 9, 2011). Most of them were very surprised and they were excited with funny images. For example, the children in class B laughed a lot when they saw a cow milking another cow for its bowl of cereal. Nevertheless, they were attracted most by the games. While playing the games "The wheel of fortune" and "Pelmanism", most students in both classes raise their hands and yelled "teacher, me, me”. Particularly, most boys and girls in class A and most boys in class B stood up to draw the author's attention to them. Noticeably, some boys in class B loved the game "The wheel of fortune" so much that they drew "The wheel of fortune" on the floor, used a marker as the hand and played in groups in their beak time (see Figure 5).

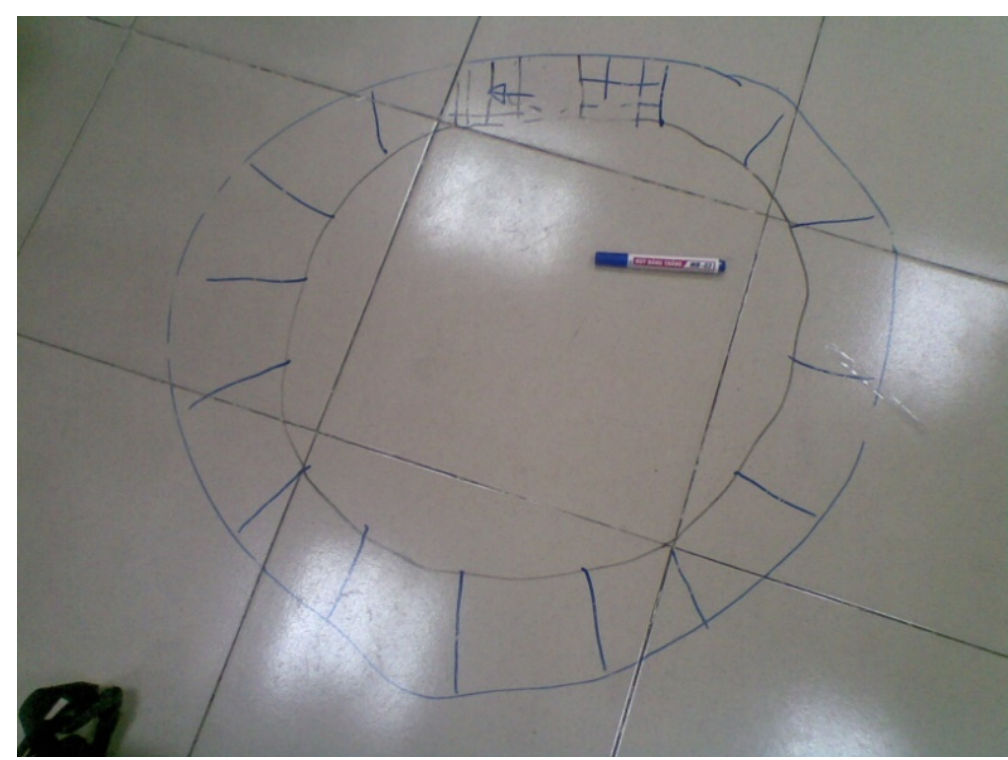

Figure 5. "The wheel of fortune” drawn on the floor by some boys in class B. 
Importantly, activities designed using multimodal texts changed "quiet" children in both classes. A few children who had never raised their hands before enthusiastically joined with their classmates. In class $\mathrm{A}$, there was a boy who always refused to join with their classmates in activities; in class B, four out of five girls usually sat in silence. However, they raised their hands to be called to play the game "Pelmanism" and they really liked images presented with PowerPoint; and as a result, they took part in activities actively.

The multimodality highly engaged children in activities were also recorded by the author's assistants. In one of his assistant journals showed that children participated in activities instead of talking, making noise, or looking at the clock. Some of them did not sit silently as they had ever done before. The author's two assistants stated in interview sections that adopting multimodality made the classes livelier and more interesting. The assistant in class B responded that: “Some girls told me that previously they didn't like to raise their hand although they knew how to answer the questions, but they changed a lot. They were more active" (personal communication, October 23, 2011).

In regard to the text which was the most attractive to children, the data collected from the teacher observations, the teacher's assistants journals, and the interview sections showed that the games designed from flashcards, and the combination of images and written texts motivated children most in both class A and B, but it is difficult to identify which of three games motivated children most. Boy A said that he liked "ball-throwing" and "Pelmanism"; meanwhile, girl A and boy B stated that they loved playing "The wheel of fortune". Partly agreeing with boy A, girl B informed that she preferred "Pelmanism”. Sharing the author's students' point of views, his assistants agreed that the games "The wheel of fortune" and "Pelmanism" were more interesting, but they also agreed that "ball-throwing" could also motivate children.

In addition, most children could recall well the words they had learned with multimodality. After learning words with multimodal texts, most children could use them in speaking and they could also recognize the words they had learned in listening activities. More importantly, all of them could recognize the relation between the images and the words. As a result of that, most of them could write down the words on their cards after seeing the images in spite of the fact that a few students had mistakes in spelling. Moreover, examining their test papers led to a comment that most students in both classes could come to know the words they had acquired with multimodality in listening and reading sections. That made a significant contribution to their good result. Most of them had excellent or very good scores (only one student in class A and one student in class B got good scores). Remarkably, the girls in both classes achieved higher score than the boys although they were not as highly motivated as the boys in some activities.

\section{Discussion}

Multimodal texts adopted in this research could motivate Vietnamese primary school children at different ages. Children at the age of seven to 11 highly engaged in activities designed by using written texts, flashcards, and images including both still and moving ones searched from the internet. The children showed their more interests in learning vocabulary. The manifestations of being bored with learning such as talking, sitting in silence, or looking at the clock on the wall, etc., as Ornstein (1995) described disappeared. However, the activities designed for this research could only produce extrinsic but not intrinsic motivation. Most children actively participated in the activities because of their enjoying fun, playing games, and having a sense of winners. Although some boys in class B drew "The wheel of fortune" on the floor to play and learn vocabulary 
with each other without any enforcement, that is also extrinsic. Anyway, that the activities could motivate the children is a considerable success because motivating children, as Mast (1937) claimed, is difficult. Moreover, because the children in the context of this study have to learn English at weekends after their hard-working weekdays in their primary school, motivating them in learning is an enormous challenge.

As discussed above, multimodal texts motivated the children in this study, but the way they were adopted is a crucial issue which needs to be explored. The fact that flashcards and images searched from the internet were used for presenting vocabulary could only draw the children's attention. But it is not sure that they can be used to motivate the children for many times. In the author's practical experience, only flashcards which were used to present the meanings and pronunciation of the words were ignored by most children. Additionally, although Kayaoglu, Dagakbas, and Ozturk (2011) found that animation motivated students in learning vocabulary, how long it gets trite to them is unknown. However, the experience gained from this research is that flashcards and images combined with written texts should be used as resources for designing different activities-like games in order to bring children with new feelings. Gul Keskil and Pasa Tevfik Cephe (2001) quoted in Harmer (2007, p. 82) confirmed that the game is one of techniques children like most.

Harmer (2007, p. 83) also concluded that children easily get bored with the same activities, so it is necessary to change their activity about every 10 minutes. This paper comes up with that suggestion. Within around 50 minutes for teaching vocabulary in each section, three different activities-like games designed maintained the children's interests in learning words. That pose a challenge that as many new ideas as possible are needed, leading to a recommendation that the school should encourage its teaching staff to contribute their ideas of teaching and share them with one another.

Who was more motivated: the boy or the girls, the older or the younger? This question was also examined in this paper. Yeung et al. (2011) concluded in their papers that boys are more motivated than girls, but that did not properly happen in this study. The difference in the level of motivation between the boys and the girls crucially depended on activities. In "ball-throwing" and "The wheel of fortune" games, the boys more highly engaged, but in "Pelmanism" there were not any differences. Nevertheless, the way some girls showed their interests was not the same as the boys. Some of them did not yell, dance, or stand up, but only raised their hands and laughed lightly.

Yeung et al. (2011) also commented that the younger is more motivated. Once again, that is not in accordance with what was found in this study. The children at different ages (from seven to 11) were motivated by the same forms of activity designed for teaching vocabulary; even the older children were more motivated, because they found easier to follow their teacher's instructions of how to do activities. However, the children at the age of six were not investigated in this study due to the fact that the classes the teacher was assigned at the time this study was conducted were not for the children at that age. Consequently, this issue needs to be examined more carefully by one further research on a larger scale with the participation of primary school children at the age of six to 11 .

Above all, what was found in this research correctly reflected what Tella (2007), Putman and Walker (2010), and Yeung et al. (2011) argued in their papers that motivation has a direct influence on learning outcomes. Although there have been different point of views on the relation between multimodality and vocabulary learning outcomes as reviewed in the section of literature review, this research showed that children could recall the words they had learned well with the support of multimodality. They were 
motivated, resulting in their interests of learning new words. That greatly contributed to their impressive midterm examination result. Therefore, it is recommended that multimodal texts should be used in a larger scale in the context of Vietnam USA Society in which the objectives of improving children's communicative ability in English and scores in exams are set.

Moreover, the application of multimodality made children follow the usual procedure of vocabulary teaching and learning without any enforcement. McCarten (2007, pp. 20-21), and Jalongo and Sobolak (2011) suggested that when teaching vocabulary, teachers need to draw students' attention to the words they are teaching, then use suitable techniques to clarify their meanings and pronunciation, and next encourage students to repeat and read aloud the words. In this research context, flashcards and the images searched from the internet and presented with the help of PowerPoint slides with impressive effects awakened children's curiosity about the words although a few students had known some of the words they were learning before. After that, the meanings and pronunciation of those words were taught by the same tools. Children then unintentionally repeated the words by playing the multimodality-based games.

Besides the benefits, using multimodality for teaching English in general and teaching vocabulary in particular should be considered because of some challenges it posed. First, what Shenton and Pagett (2007) claimed that it takes teachers much time to prepare materials was in line with what the teacher doing this research faced. Two weeks were spent on planning to teach vocabulary within two sections and do review and assessment in one section. That is really difficult for busy teachers. Second, knowledge of technology as HAI and LI (2007) informed in their paper can create a barrier that prevents good ideas from coming true. Before using the software of PowerPoint to design the games for conducting this study, the author had got some ideas from game shows on TV channels and tried to examine if there were any applications for teaching and which software was suitable for designing games. After that, the author shared his ideas with some of his colleagues who are very interested in technology to take their advice. Then it took the author some more weeks to sit before his laptop to manage to design as many games with PowerPoint as possible and from which the best ones were selected. When the research was conducted, some of them were used with some appropriate adjustment. Third, adopting computer games for teaching, according to Graham (2009), requires both teachers and students to learn new skills. To teachers, the kills of using computer and designing games as discussed above are important. To students in class A (in this research context), some of them were very confused with clicking the mouse to play games at first. After being instructed again and again, they were more proficient.

What discussed above also indicates that the roles of teachers do not reduce as the teachers in Ryan et al.'s (2010) research context complain. To most Vietnamese primary school children, they cannot design games and share with each other in learning as what the children did in the research by Graham (2009). Therefore, the teachers still decide how to teach and what to make the lessons interesting. So, it is recommended that the school pay for the games designed by its teaching staff which can be applicable in classrooms. Only that can encourage them to work harder and then teach better.

Despite some achievements stated above, there were also some limitations that are needed to be examined as follows. The first one was that some technical problems partly affected some children's level of motivation. For example, the projector did not work in class B while all children were looking for playing games. Therefore, some looked disappointed. Around 10 minutes later, it was fixed by a maintenance staff. The second one was 
that very little information was received from children interviews due to the fact that appointments were not made after or before classes. The reasons for this were that some children could not go to school before their classes on Sunday mornings or their parents were too busy to take them to go to school earlier, and they could not wait until interviews ending to pick up their children. Consequently, interviews had to be conducted in break time when children only liked going out for playing with their friends. That led to the possibility of not fully exploring what they really thought about the multimodality-based activities as Kortesluoma et al. (2003) advised that children interviews reflected faithfully their feelings. Lastly, like what Honan (2008) complained that it is the syllabus that can affect teachers' decision, the selection of activities in this research were limited by the time set for each class, and the lesson structured in the text books. That led to the fact that there were fewer opportunities to get more reliable data.

\section{Conclusions and Recommendations}

Primary school children at different ages in this research context changed their attitudes towards learning vocabulary under the adoption of multimodality. They did activities actively and did not ignore what their teacher had suggested. By using different modes of texts to design activities-like games with the support of technology, the teacher could engage the children in the procedures of teaching vocabulary which had not been followed before. Noticeably, both boys and girls were motivated although there were differences in their ways of showing interests in activities. More importantly, a few students who the teacher encountered difficulty engaging in lessons changed their behavior towards learning new words. Via assessing how children recalled the words they had learned with multimodality by the ways of observing how they did speaking, listening, and reading activities, and examining their mid-term examination result, it is also concluded that they acquired vocabulary very well.

It is also noticed that the modes of text were adopted in an appropriate way in this research. They were not used individually but some of them were combined with each other. Furthermore, they were used as sources for designing activities (games) making children more enjoyable in learning. The way that three different games played also brought new feelings to children in each section, leading to the capability of maintaining their interests in learning vocabulary.

However, using multimodal texts to conduct this action research also posed some challenges for both the teacher and children. The first one was that the teacher spent much more time than before to plan the lessons. That requires English language teachers in Vietnam to make choice: teaching more or teaching less and saving more time for planning. The second one was that more knowledge of technology was needed. The third one was that teacher and children had to learn new skills.

To utilize multimodal texts for teaching and learning English extensively, this research produces some following recommendations. Firstly, a further study should be conducted with the aim of investigating the roles of multimodality in motivating primary school children at the age of six to 11 in learning vocabulary because of the fact that this research could not be carried out in a class for the children at the age of six. It is also suggested that some further studies on the roles of multimodal texts in teaching vocabulary and English skills for adolescents and adults. Secondly, the school should encourage its teaching staff to adopt multimodal texts in a large scale in teaching children vocabulary. Thirdly, the school also needs to develop a policy on motivating the teachers in contributing more new ideas of using multimodal texts in teaching. 


\section{References}

Acha, J. (2009). The effectiveness of multimedia programmes in children's vocabulary learning. British Journal of Education Technology, 40(1), 23-31.

Al-Haj, A. M. (2011, May). Enhancing motivation in the EFL classrooms is the solution (a case study of second schools of the Gezira state, Sudan). Journal of Language Teaching and Research, 2(3), 524-529.

Allen, F. V. (1983). Techniques in teaching vocabulary. Oxford: Oxford University Press.

Bearne, E., \& Wolstencroft, H. (2007). Visual approaches to teaching writing: Multimodal literacy 5-11. London: SAGE.

Chappelle, C. (2003). English language teaching \& technology. Amsterdam: John Benjamins.

Cotton, R. E. D., Stokes, A., \& Cotton, A. P. (2010, August). Using observation methods to research the student experience. Journal of Geography in Higher Education, 34(3), 463-473.

Gomleksiz, N. M. (2001). The effects of age and motivation factors on second language acquisition. Firat University Journal of Social Science, 11(2), 217-224.

Graham, L. (2009, July). It was a challenge but we did it! Digital worlds in a primary classroom. Literacy, 43(2), 107-114.

HAI, P., \& LI, J. (2007). Vocabulary acquisition in multimedia environment. US-China Foreign Language, 5(8), 5-59.

Harji, B. M., Woods, C. P., \& Alavi, K. Z. (2010, September). The effect of viewing subtitled videos on vocabulary learning. Journal of College Teaching \& Learning, 7(9), 37-42.

Harmer, J. (2007). The practice of English language teaching. Harlow: Longman.

Harrett, J., \& Benjamin, T. (2009, November). Travel with a Time Lord: Using media to enhance literacy. Literacy, 43(3), 134-142.

Honan, E. (2008, April). Barriers to teachers using digital texts in literacy classrooms. Literacy, 42(1), 36-43.

Jackson, P., \& Sileci, S. B. (2012a). Everybody up 1. Oxford: Oxford University Press.

Jackson, P., \& Sileci, S. B. (2012b). Everybody up 3. Oxford: Oxford University Press.

Jalongo, R. M., \& Sobolak, J. M. (2011). Supporting young children’s vocabulary growth: The challenges, the benefits, and evidence-based strategies. Early Childhood Education Journal, 38, 421-429.

Kayaoglu, M. N., Dagakbas, R., \& Ozturk, Z. (2011, April). A small scale experimental study: Using animations to learn vocabulary. The Turkish Journal of Educational Technology, 10(2), 24-30.

Kortesluoma, L. R., Hentinen, M., \& Nikkonen, M. (2003). Conducting a qualitative child interview: Methodological considerations. Journal of Advanced Nursing, 42(5), 434-441.

Lancaster, L., \& Rowe, D. (2011). Editorial. Journal of Early Childhood Literacy, 9(2), 114-116.

Landen, L. J., \& Willems, L. A. (2001). Do you really know how to motivate children?. Education, 99(3), 283-286.

Lewis, M., \& McCook, F. (2002, April). Culture of teaching: Voices from Vietnam. ELT Journal, 56(2), 146-153.

LI, C. (2009, December). A research on second language acquisition and college English teaching. English Language Teaching, 2(4), 57-60.

LU, M. F. (2008, August). Teachers' role in vocabulary teaching: Strategies for vocabulary teaching. Sino-US English Teaching, 5(8), 1-6.

Marsh, J., \& Singleton, C. (2009). Editorial: Literacy and technology: Questions of relationship. Journal of Research in Reading, 32(1), $1-5$.

Mast, T. E. (1937, September). Motivating factors in child learning. Child Development, 8(3), 273-278.

McCarten, J. (2007). Teaching vocabulary: Lessons from the corpus, lessons for the classroom. Cambridge: Cambridge University Press.

Ornstein, C. A. (1995). Motivation and learning. The High School Journal, 78(2), 105-110.

Putman, M., \& Walker, C. (2010). Motivating children to read and write: Using informal learning environments as contexts for literacy instruction. Journal of Research in Childhood Education, 24, 140-151.

Rezaee, A. A., \& Shoar, S. N. (2011, June). Investigating the effects of using multiple sensory modes of glossing vocabulary items in a reading text with multimedia annotations. English Language Teaching, 4(2), 25-33.

Robins, G. (2011, Spring). Music and multimodal text. English Four to Eleven, 41, 4-7.

Ryan, J., Scott, A., \& Walsh, M. (2010, August). Pedagogy in the multimodal classroom: An analysis of the challenges and opportunities for teachers. Teachers and Teaching: Theory and Practice, 16(4), 477-489.

Sabet, K. M., \& Shalmani, B. H. (2010, June). Visual and spoken texts in MCALL courseware: The effects of text modalities on the vocabulary retention of EFL learners. English Language Teaching, 3(2), 30-36. 
Shahrokni, A. S. (2009, December). Second language incidental vocabulary learning: The effect of online textual, pictorial, and textual pictorial glosses. TESL-EJ, 13(3), 1-17.

Sharma, P., \& Barrett, B. (2007). Blended learning. Oxford: Macmillan.

Shenton, A., \& Pagett, L. (2007, November). From "bored" to screen: The use of the interactive whiteboard for literacy in six primary classrooms in England. Literacy, 41(3), 129-136.

Tella, A. (2007). The impact of motivation on student's academic achievement and learning outcomes in mathematics among secondary school students in Nigeria. Eurasia Journal of Mathematics, Science \& Technology Education, 3(2), 149-156.

Tomal, R. D. (2010). Action research for educators (2nd ed.). Plymouth: Rowman \& Littlefield Education.

Wilmot, R. (1979). Participant observation: A methodological approach to the study of halfway houses for alcoholics. British Journal of Addiction, 74, 369-375.

Wyatt-Smith, C., \& Kimber, K. (2009). Working multimodally: Challenges for assessment. English Teaching: Practice and Critique, 8(3), 70-90.

Yeung, S. A., Lau, S., \& Nie, Y. (2011). Primary and secondary students' motivation in learning English: Grade and gender differences. Contemporary Education Psychology, 36, 246-256.

Zarei, R. G., \& Khazaie, S. (2011). L2 vocabulary learning through multimodal representations. Procedia Social and Behavioral Sciences, 15, 369-375. 